\title{
Digital Asset Management: A Lowdown on Intricacies of Digital Rights and Permissions
}

\section{Venkata Naga Satya Surendra Chimakurthi}

Solutions Architect, CDBDX-Platforms-DAM (Digital Asset Management), Cognizant Technology Solutions, Dallas, USA

*Corresponding Contact:

Email: chvnssurendra@gmail.com

\begin{abstract}
The adaptability of digital asset management has prevailed enormous businesses and individuals who desire to manage information effectively. The criteria of this paper will revolve around the in-depth intricacies of digital asset management, its functions, significance, and categories of DAM. The introduction of digital rights and permissions aligned with highlighted copyright permission. Initializing from manual asset management and proceeding towards digital asset management, media asset management, and finalizing at massive content management, these terms seem to be striving to explain a unified thing. However, each domain of asset management has separate aspects of managing information. Every organization will opt for its criteria of approach for managing the assets that rely upon the environmental, current cultural, and financial state of the company.
\end{abstract}

Key Words: Asset Management, Media, Content, Financial Strategy

\section{INTRODUCTION}

The following definition will elaborate on digital asset management: "Digital asset management (DAM) is a business procedure that will assist the organizations in storing, organizing, finding and retrieving rich media and managing the digital rights and permissions. The term rich media asset revolves around photos, music, podcasts, animations, and other multimedia content." OR "Digital asset management is a strategical business approach that will incline revenues while reducing workflow and process cycle times". The discussion of asset management had separate significance in various sectors of human interests and is employed loosely by businesses and individuals to describe the requirement of managing information in this digital age. In this advanced age of the 21st century where digitalization is prevailing in every field of life, there is the utmost need for the adaptation of law that will safeguard and protect the fundamental rights of every individual (Wager, 2005). The criteria of digital management of assets incorporates the composition of a log and construction of a validated and operational framework to manage and secure digital properties and probe an authentic functional that allows terminal-users to recognize, detect and redeem a digital asset. In simpler words, a package of databases records compiling up all the essential and confidential information of terminal users has referred as DAM or digital 
asset management. The single record present in database comprises of metadata elaborating the identity of the documents, information about its usage, its format or category of content. A significant feature of digital asset management (DAM) software relies on the fact that this software is frequently used to create and manage databases and assist companies to sort out rich media in a cost-effective manner.

However, the retention of DAM has not proven to be convenient till the termination of $20^{\text {th }}$ century due to the unavailability of various systems. The declining trends in the processing phenomena and storage of databases in the form of disks has acted as the pre-dominant contributing factor. There is another supplementing aspect that is an ever-incrementing transmission capacities of computer networks, both within a long-distanced mileages and local areas (Manavalan, 2018). Numerous products have been outlined with an intention to manage the massive depositories and can automatize repetitive and labor-intensive tasks (Manavalan, 2019a). It encompasses the indexing and cataloging of puissant search engines and digital content that everyone is approaching and using to discover their desired content and find solutions of their queries.

\section{LITERATURE REVIEW}

Marketing and premeditated transport network sections play an important role in all kinds of businesses and establishments. From nonprofits and small trades to Fortune 500 businesses, advertising and communications play an important role in helping governments make their aims (Zerfass \& Volk, 2018). Although the importance of strategic marketing is incorporated, there are a few experimental studies on how the dynamics and functions of marketing add value to the business (Moss et al., 2017). Marketing serves the business by communicating a message within and outwardly through a variety of media channels that support day-to-day processes, lay the foundation for future success, and tell the planned growth of the association. Strong team dynamics are essential for strategic marketing and communications departments to successfully make their goals. Your role in marketing has habitually aligned on two primary functions. One is publicity managing the relationship, and the other is publicity creating assets such as images and text. In recent research, this role has been expanded to contain experts and business advocates (Zerfass \& Volk, 2018). Although research in this area is inadequate, one study initiates that although there is no leading management structure model, roles and tasks fall into outside and inside communications, crisis management, media relations (Manavalan, 2019). The study also acknowledges that an effective management structure contributes to a variety of competencies such as resource allocation, ability to sustenance company functions, clear controller of accountability and tasks, and ability to work in a joint environment (Moss et al., 2017). DAM systems are commercial enterprise software, but unlike much software in this group, DAM systems are not preconfigured. As an alternative, the formation is subject to the buyer's requirements. These parent terms contain asset management and find keywords, metadata meadows, and user permission controls (Carner, 2019). When an organization is ready to build and carry out a DAM system, there are two methods. The first is an old-style technology-driven approach, where alignment limits the sustainability of options on the platform of your choice. The other is a human-centric approach that covers the needs of the end-user from the very opening to regulate the configuration of the policy (Carner, 2019). For traditional technology-based approaches, DAM systems are selected based on businesscentric goals set by management and the financial influence on the association (Wager, 2005). 


\section{Methodology}

In evaluating the conventional regimes of cataloging and indexing the computerized valuables of composers, the manufacturers of multiple products have leveraged productive and in-depth investigation work to attain the proper apprehension of speech, recognition of various digital characters, conceptual analysis and many other intricate aspects to secure the digital assets from cyber-conflicts. An extensive implication of these ideas demands considerable strengths of processing to furnish content ingesting in a real-time process, which is crucial facet in various audio-video applications, movie content, and another media or documentation. The introduction of the low-cost and preponderance computer workstations will compose such technology commercially viable, which is somewhat taken for granted (Wager, 2005).

Creative Services

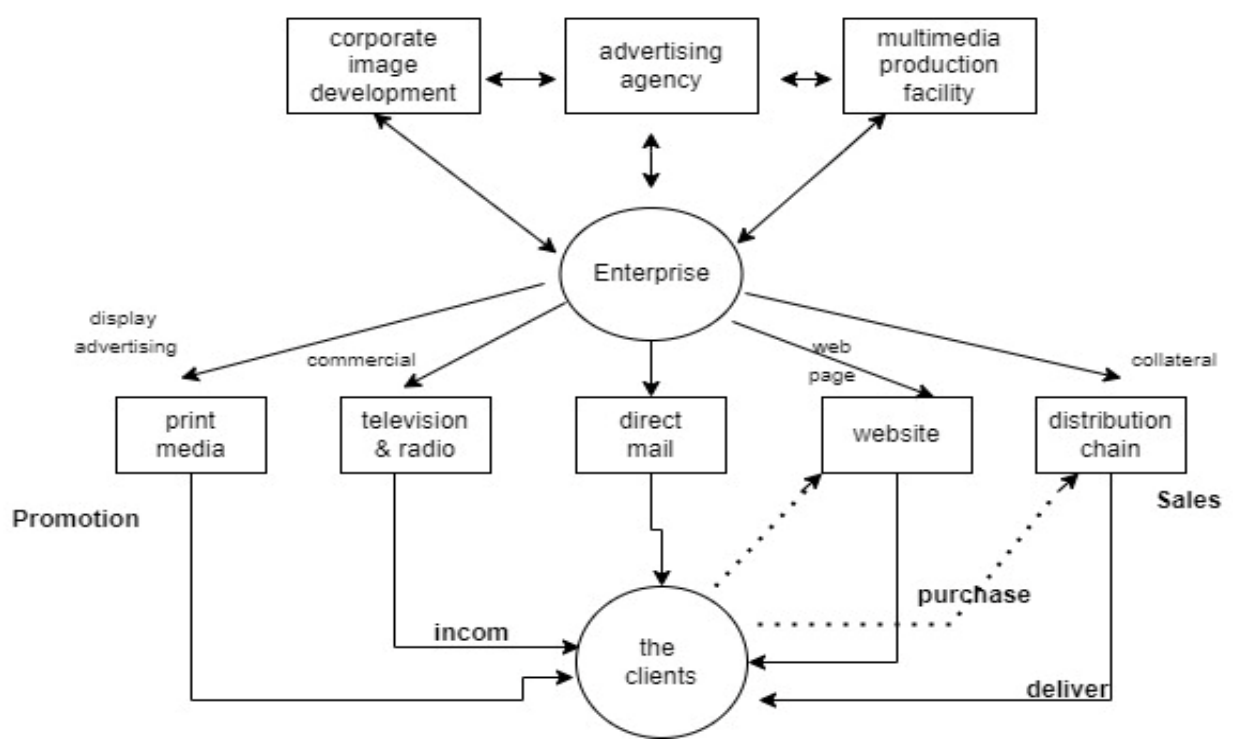

Figure 1: Exchange of content in a corporate enterprise

The creation of media content has extended to various guises in the field of modern businesses. The figure illustrated below will depict particular compartments in a collaborative organization and the material of data and content they are producing. Conventionally, each department will manage its media content, commonly with some formalized filing structure. The criteria of global brand management require the enterprise-wide sharing of content, it will prevent the corporation from bug chaos, wrong logos, out-of-state corporate images, and link-rot on the websites.

\section{Digital Asset MANAGement}

In conventional printing and publishing industry the managerial duty of documents has already proved its worth and weightage. An efficient deployment of large websites has a stalwart connection with content management. Concerning the incline in several distribution platforms, the basic and advanced requirements of organizing a brand and the longings to control the rates and cost criteria have progressed towards the convergence of production and creative procedures organically. A huge enterprise or a company is unable to proceed a successful multimedia project, a printed document and web fabrication unit in an isolated system. The major term that applies to this converged content is rich media (Austerberry, 2012). 
Depending upon the versatility of various enterprises, the field of convergence will remain limited to content creation in certain cases. However, it can expand to the management of corporate communications and marketing collaterals. For instance, if a marketing department has set up a show booth then it is similar to a CD-ROM organized by a training department in the digital perspectives.

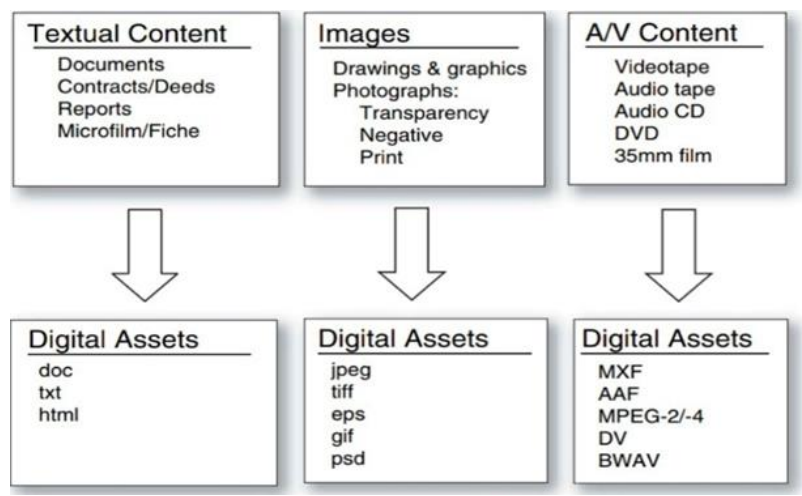

Figure 2: Digital assets originates from content

The companies or organization that are communicating directly to the consumer may require a commercial iTV that will relate to website of respective company. In this way, the consumer can view all the pages of web and may demand and able to see added information. However, it is mandatory that all these categories of content oriented towards media components should portrays the obvious and genuine image of the corresponding brand and retain highlevel asset management of the customer.

The systems used for managing rich media assets have laid down their foundations on similar principles employed for content management. The intricacies of rich media have enlightened the fact that the vitality of DAM is obvious and it plays pivotal role in nurturing the control costs and operational competency.

The initiation of producing the rich media launches from conventional methodologies of recording the audio and video content and enhanced latterly with the added features of text synchronization, elements of 3D characters and graphical illustrations. The modern workflow adopted for production of content have elevated potential of digital content by symmetrical and influential content for the user. It has manifested that it is far better that the linear conventional regime of workflow specifically adopted for television production that incorporates creative talents of people physically. The major paramount is the provoking pressure to low down the production cost in an effective and smarter way. However, the digital markets are expanding at an exponential rate and interrogating a publication of content in profuse variants of formats along with digital asset management to ensure security for their users (Currall and Moss, 2009).

\section{Historical and future perspectives of DAM}

The emergence of technological era especially the incident of origin of desktop publishing had taken place in the late 1980s. This event has acted as a turning point for printers, advertisers, and publishers to digitalize graphics, text, and photography. The files which are specifically bigger for most internal hard drives were shifted to external media with simple labels of metadata. They were arranged in plain, hierarchical folders and files. 
Canto software was the first inaugurator of digital asset management systems, named Cumulus, and this event took place in 1992. It had proved as a standalone solution, onpremises, featuring thumbnail previewing, search capabilities, and metadata indexing. In this way, earlier solutions related to DAM have made it easier to find, verify and retrieve the assets, but files are still not easy to share. The quick revolution of DAM into integrated libraries has allowed the delivery of content into a variety of systems, devices, and repositories. The assets have plugged into various applications and met specific requirements through APIs or application programming interfaces effectively and rapidly.

It is common for AI capabilities to be penetrated by DAM. It is encompassing crossreferencing and intelligent tagging, which include voice and video recognition. The utilization of machine learning has enabled the DAM systems to anticipate the needs and make recommendations to users. These elements will assist in performing the market task swiftly, often within minutes or even less time. A swift overview of a general dictionary elaborates that the term usually indicates towards property, personal belongings and individual's private treasures. A similar connection with chattels is also applicable to digital content and digital asset. Another technical term associated with a digital asset is that if the user has cognitive rights of property associated with the digital content then that particular content has also declared as a digital asset in the universe of internet. Therefore, in view of these clarified backgrounds, two verified institutes, IPMP abbreviated as intellectual property management and protections and DRM known as digital rights management are responsible for composing an authorized sketch for asset management to render protection and security to the publishers and composers content.

The similar set of systems that secure rights and obligations of property can also be employed to secure personal and confidential information of publishers and digital asset owners, so DAM is frequently employed for interior dissemination of sensitive and significant information both on personal and commercial platforms. The criteria of asset management is extensive enough and not only revolves around the rights or permission management, as it will compose a minute but vital portion of the total digital content produced.

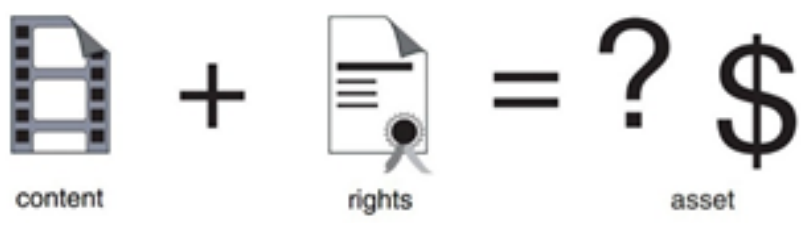

Figure 3: An asset is content with the supplement of right to use

Eventually, the most enticing characteristics of asset management on digital forums is that it will dispense an outline for the monetization and cost management of variety of assets like media assets. Personal account, business profiles and brand websites (Wager, 2005). The management of assists either in the digital or physical is an extensive field and requires high level of scrutiny to ensure its requisites. The regime of searching through an inventory of trade business and websites for asset management will depict the systems of shelving for ornamented and precious file management achieved with the aid of software. It will also encompass tape cassettes, silos of robotic data tapes, disk arrays contain the hardware vendors, as well as solution sets containing the software's with end-to-end encryption that is able to recruit, search, manage and, retrieve and index a profound amount of video or audio content.

To be more precise, DAM will furnish the users will provide a sensible administration and exploitation of a massive repository of asset. The system for asset management dispenses a 
wholesome package of tools for the publishers, composers, and the terminal users of a particular web page, media content, and socializing application to perfectly allow the administrators to avail the perks of asset management. There are various formats of media assets, for instance, audio and video clips, pictures, research work, documents including the HTML content and much more. Tether exist a strong associations and interlinkages between these assets. The sharing of these files occurs through various platforms both on internal and external forums like an enterprise personal record and publicly on social websites. The digital content referred as assets may be rented, sold, syndicated, and traded. The architectural system of DAM must be elastic enough to furnish and fulfil all the required features. There are certain facilities and organized systems that are particularly found in a DAM system.

The extension of asset management occurred through route that passes through websites and internet pages. It will provide the latitudes to authorize and dominate the content at the main area of desktop, which is secluded from content manufacturing unit. The availability of access to these content is possible in multiple ways, such as the composer can approach the content directly from the enterprise, over the internet, or another search engine verified by the asset management company (Wager, 2005).

\section{DAM Significantly}

DAM or digital asset management is the ultimate way to provide a secure repository for a wide variety of assets composed by various people in the digital world. If you are analyzing that which way is best to secure and store all of your digital assets including the marketing content like YouTube videos, Instagram posts and Facebook information videos? The systems established for digital asset management will come up with all your repercussions and even enhance your creative process (O'Gorman et al., 2019).

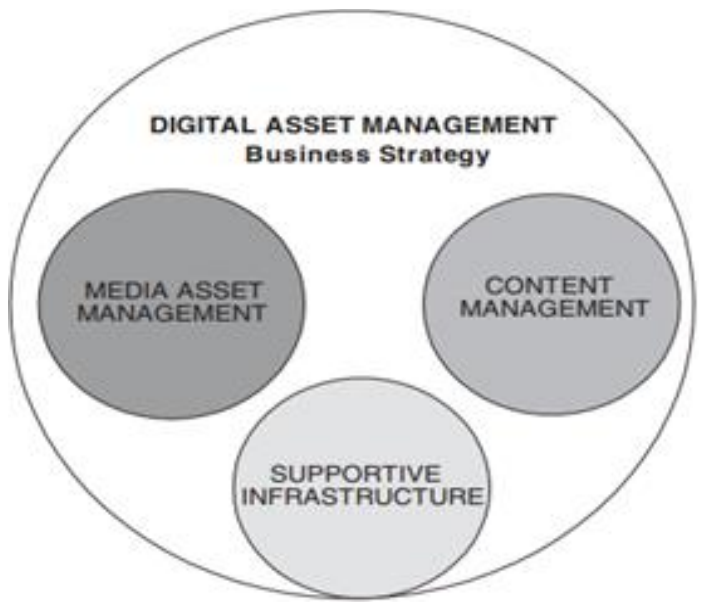

Figure 4: Constitutes of strategy of DAM

\section{Functions of DAM}

Digital asset management has ample functions that have been accomplished with high-end precisions and accuracies in this domain. Perhaps, among the eminent reasons to specifically focus on DAM is the capability of the system for protecting, securing, and organizing your privileged and confidential assets. It is an obvious fact that the systems designed for DAM will lead towards iconic launching of digital world with high end security and asset management. 
Table 1: An outline explaining a guided DAM strategy

\begin{tabular}{|c|c|c|c|c|c|c|}
\hline \multicolumn{7}{|c|}{ DAM STRATEGY } \\
\hline \multicolumn{2}{|c|}{ Production Initiative (MAM) } & \multicolumn{2}{c|}{ Operations Initiative } & \multicolumn{2}{c|}{ Sales Initiative } \\
\hline $\begin{array}{c}\text { Graphic } \\
\text { Project }\end{array}$ & $\begin{array}{c}\text { Storage } \\
\text { Project }\end{array}$ & $\begin{array}{c}\text { Editing } \\
\text { Project }\end{array}$ & $\begin{array}{c}\text { Telecom } \\
\text { Project }\end{array}$ & $\begin{array}{c}\text { Content } \\
\text { Management } \\
\text { Project }\end{array}$ & $\begin{array}{c}\text { CRM } \\
\text { Project }\end{array}$ & $\begin{array}{c}\text { Inventory } \\
\text { Management }\end{array}$ \\
\hline
\end{tabular}

It will encircle the following functions:

File accessibility and sharing: Digital asset management is casually cloud-based, therefore the foremost function that DAM will serve is its exclusive characteristics of distributing the files wherever the composer demands (Chimakurthi, 2017). The types of systems established for DAMs have designated with features of efficient and cheaper results. It is due to their network of servers placed remotely and convenient access to web browsers.

A straightforward organization: The ultimate way to attain a flow of organized and clear firms, the target can be achieved by stalwart interlinks with DAMs. Due to placement of all elements in a consolidated location, it is simpler and convenient to find the files of your properties lying on digital forums. It will be advantageous for a team working since it is easier to to access a single unit than approaching the assets in various depositories. So, it will dispense an overwhelming experience for a digital asset management company.

Rapid access towards files and data: With the practicality and structured organization of Digital asset management, it becomes smoother to access files and other affiliated data in the files. The systems adopted by enterprises will do DAMs will nullify the hustle of probing into folders within folders, and provide a complete section for a unified file with its specificity. Digital asset management has played a pivotal role in balancing the massive amount of information at one place along with prolific security measures.

Digital distribution and publishing: The complementary function of Digital asset management has bridged towards digital distribution and publishing. Since DAMs orients around the keeping of information in databases at one place, in a similar way, there is availability of tools used in managing the asset under a single roof. In addition to this, DAMs will enable the organizations to expand their assets on a highly advanced services for distribution like 3PL providing services.

Perfect management of Brand: The key feature in coping up with your marketing competitors is hidden in brand consistency. With the assistance of DAM, businesses can manage the designs of their brands and other crucial information for users in an effortless way. The characteristics of DAM will also allow proficient management for your brand by enabling page customization as well as attaining access to plethora of files that is assistive for collaborators and key stakeholders of the organization.

Rich media asset management: The compatibility of digital asset management with rich media is obvious as it encompasses the creation of audio, videos, and images. The extensive domain of DAMs will render the users a to approach a larger preview of their saved files.

Availability of company content at one place: A highlighted perk of digital asset management is the allocation of files in a single repository that will resource the 
member of digital platforms with numerous benefits. For instance, the team members can share, collaborate, and compose ideas within a DAM system. It is only possible to manage all the tasks under one roof of a digital asset depository (OGerman, 2019).

\section{Categories of managements adopted for digital assets}

- $\quad$ LAM- LIBRARY Asset management: A spacious criteria accommodates in this category of asset management that will encircle a bulk of storage that is kept in the database. These assets will recruit all types of assets such as a register or library consisting of various files such as videos, photos, audios, text documents, research publishing and much more.

- $\quad$ BAM- BRAND asset management: It will direct towards the management of securing branded assets within a centralized database. This specific type of digital asset management will implicate edits, consults, and updates to execute the management of digital brands.

- $\quad$ Production asset management: PAMs are specifically designed for protecting and managing visual or digital assets involving any category of production for TV soaps, movies, video games, and all types of live media action.

- Cloud-based digit asset management: It is one of the most frequently used types of digital asset management. Cloud-based storage will enable the users to utilize digital assets that have been stored and backed up into a secure archived within a mechanized DAM system. With a cloud-based solution, more companies have more creative benefits and rapid access to succeed with their asset and content management processes (O'Gorman et al., 2019).

\section{Who Utilizes Digital Asset Management?}

The list of users getting benefits from DAM systems is countless. There are two major categorizations of users using the DAM systems:

- $\quad$ Exterior users

- Interior users

\section{Interior users}

The term of interiors users indicates the users who are engaged inside an organization or a business. They specifically use information and content from the DAMs regularly. These are eminent examples of departments that are considered as interior users.

- Creative professions: It comprises photographers and graphic designers that are desiring to have everything compiled up in a unified depository, specifically the content that they have designed and composed. The creatives will also have accessibility to multiple categories of content relating to the company that can be used for product distribution. Digital asset management systems will encourage the creatives to use it for their tools.

- $\quad$ Packaging asset management: The use of DAMs for packaging assets is a remarkable way. It will furnish the ability to track package processing along with a regular update of its appearance. Digital asset management systems have been designed with supremacy that will let the users visualize content in a 3D form that can be an alternative to organizing all types of assets. 
- Legal sector: Digital asset management can be used to track down other users that are downloading prohibited content. The major reason for employing the DAMs by legal teams is for the maintenance of proper rights to digital assets that are owned by a particular company. The digital asset utilization has overlooked expiration dates to the said digital asset.

- IT department: IT and tech professionals will utilize the DAMs to track the databases and for assurance of their correct usage. Hence, it's significant that your company appoints a DAM manager that can collaborate with IT professionals when it comes to the matter of other systems with your digital asset management system.

\section{Exterior users}

The users who are external to the enterprises and organizations also have access to these DAMs, but not consistently similar to internal users. There are the following categories of external users:

- Distributors: The selling and promotion of the product is a critical task for distributors and requires digital asset management for accomplishing this task. As it involves distribution to other businesses, DAMs are one of the most effective ways to adopt when the distribution task demands the usage of images for product promotion and other features of businesses.

- Agencies: Agencies are unable to access digital content such as logos, photos used for branding without the essence of digital asset management. Agencies are frequently using DAMs as a proactive tool to execute the campaigns.

- $\quad$ Partners: The initiation of a partnership with other businesses is co-related with Digital asset management systems. As DAM is the marvel of remote tools and it will allow you to work with your business partner proficiently throughout the project (O'Gorman et al., 2019).

\section{Digital Rights and Permissions}

Digital right is an extended branch of sets of rights set out in the universal declaration of human rights by the United Nations as applied to the internet and online world. The major purpose of this set of rights is to guarantee access to the internet and assure the common asset belonging to the whole of humanity. The lack of international consensus has led each country to establish its digit rights centers (Subramanya and Yi, 2006).

The advent of digital media and analog-to-digital conversion technologies has extensively increased the concerns of copyright-owning organizations and individuals, specifically within the film and music industry. With each copy generation, the analog media will lose its quality inevitably and in a few cases even during normal usage, digital media files are replicated an infinite number of times with no deterioration of quality. The earliest implication of Digital rights management had devised in 1983 by Ryuichi Morita, who is a Japanese engineer. The digital right management (DRM) was a software service system and based on encryption, with specialized hardware that handles the decryption and also activated the payments to be sent to the copyright holder (Zur et al., 2009).

While discussing the digital assets the scenarios of rights and permissions are somehow varying. The definition of rights is by-laws and assigned to the right holders. Contrarily, permissions are a set of privileges granted by the right holders. 
The usage of any type of content (text, image, audio, video, etc.) requires permission of owning a body, particularly for commercial purposes. Similarly, distributing pictures of assets or property may violate the rights of that person, specifically if the material is copyrighted. To avoid such troublesome situations, the phenomena of digital asset management have been introduced and DA managers are responsible for securing the assets and monitoring their usage.

The creation of Copyright laws is purely intended to maintain a balance between authors, publishers, distributors, the public, and general users. There is stalwart coherence between digital rights and freedom of expression, fundamental rights, and privacy. Digital rights are the set of regulations that will allow people to use, access, create and publish digital media along with accessing and using computers, communication networks, and devices (Dingledy and Matamoros, 2016).

\section{Significance of Digital Assets Rights and Permissions}

The relevancy of digital rights and permissions is evergreen agenda in the digital world. The responsibility of digital asset publishers and managers is significant in the field of DAM. As they are responsible for tracking rights adhered to their owned assets to avoid any legal penalties for copyright infringement. Asset management has become a crucial requirement for publishers, as it is likely that they have gathered a large number of assets over time. There are chances that these precious digital assets have transferred between parties and may even get lost in the shuffle. Hence, publishers must keep track of their rights and permissions along with the digital assets themselves (Dingledy and Matamoros, 2016).

Although digital content has been covered under copyright laws, monitoring the web to catch illegal activity is quite challenging in this prevalent digital era. Digital right management will open up a proactive approach to protecting digital content by uplifting barriers to steal it in the first place. There are various approaches and methodologies to implement digital resource management and continual efforts to establish innovative methods. The tools of DRM will operate through the routes of encryption or computer codes embedded in the digital content, it will limit the access or usage. The implication of these tools will control several devices, times, people, or periods that the content can be accessed and installed (Bechtold, 2004).

The iconic article of Frederick W. Dingledy named as "what is digital rights management?" has outlined the below-mentioned DRM tools and processes that elaborates the illegal use of copyrighted material.

\section{Management of permission}

It is a form of control limits that has permission to utilize a certain work or piece of content. The solid examples of these DRM strategies encompass software licenses and keys, IP authentication protocols, user authentication, proxy servers, regional restriction or geoblocking, virtual private networks (VPNs), designing products, and geoblocking that will only work on specialized hardware or software.

\section{Copyright protection}

The technical and digital strategies can control access by preventing users from establishing copies of a particular slice of content. They are typically implicated through encryption, which will enable the publisher to write the digital content in a code that can only be read by devices or software with the key to unlock it. This is the recommended approach and is known as 
scrambling. The evident examples of copy protection include fingerprinting, digital watermarks, and limiting the restricting copying features (Ku and Chi, 2004). Various creators of digit content employ multiple DRM strategies to restrict or control the use of work.

\section{Digital asset permissions}

The attainment of copyright permission to use digital and online content is both straightforward and complex. The permission for getting permission of using the digital content in an online or physical container such as DVDs is generally approached in a similar way as analog or traditional content. The procedure to get the permission there is a need to consider these below mentioned questions as mentioned below:

- Development of an entire multimedia electronic magazine or a blog.

- Creation and alignment of a virtual library or archives.

- Permission simply revolves around the article or a photograph on a website.

The significance of copyright permission has elaborated below:

- The protocol of protection for digital and non-digit works is similar in the case of copyright. It is mandatory to follow the rule that content on the internet is protected by copyright rules except in the case that the associated information with the content stats something else. Similarly, copyright protects digital content like the content of tv serial.

- The retention of copyright protection varies from country to country. In the USA, copyright protection lasts for a tenure of 70 years after the death of the author or composer. In various other countries like Canada, the tenure includes a lifetime plus fifty years. After the expiration of copyright permissions, anyone in the world is free to use that information.

The domain of digital work depending on its nature comprised of multiple layers of rights and variable copy-right protected works. There are numerous categories of work that require permission according to the sensitivity of the asset. For instance, websites, electronic publications, digital libraries, video games, and educational software owned by the creator must clear the sensitivity and nature of content in it (Liu et al., 2003).

\section{CONCLUSION}

The adaptability of digital asset management is widespread among large organizations and people looking to manage information efficiently. The criteria for this document center on digital asset management in-depth, functionality, semantics, and complexity of DAM classes. The entry of digital rights and licenses is compatible with known copyright licenses. This article is loosely used by companies and people to discuss the different implications of asset management in different areas of human interest and to explain the need for information management in this digital age. Digital asset management standards include regulating records, building a proven operational framework for digital asset management and security, and exploring real-world capabilities for end-users to find track, and retrieve digital assets. A noted distinguishing feature of Digital Asset Management (DAM) software is that it creates and manages databases and often helps companies organize their rich media in a costeffective way. 


\section{REFERENCES}

Austerberry, D. (2012). Digital asset management. $2^{\text {nd }}$ Edition, Routledge. ISBN: 9781136033612

Bechtold, S. (2004). Digital rights management in the United States and Europe. The American Journal of Comparative Law, 52, 323-382.

Carner, M. (2019). A human-centred design approach to digital asset management: User experience as a foundation for system-configuration design. Journal of Digital Media Management, 7(4), 357-365.

Chimakurthi, V. N. S. S. (2017). Cloud Security - A Semantic Approach in End to End Security Compliance. Engineering International, 5(2), 97-106. https://doi.org/10.18034/ei.v5i2.586

Currall, J. E. and Moss. M. S. (2009). Digital asset management. In: Encyclopedia of Library and Information Sciences, Third Edition. CRC Press: 1528-1538.

Dingledy, F. W. and Matamoros. A. B. (2016). What is Digital Rights Management? Library Staff Publications. 122. https://scholarship.law.wm.edu/libpubs/122

$\mathrm{Ku}, \mathrm{W}$. and Chi. C.-H. (2004). Survey on the technological aspects of digital rights management. In: International Conference on Information Security. Springer: 391-403.

Liu, Q., Safavi-Naini, R. and Sheppard, N. P. (2003). Digital rights management for content distribution. In: Proceedings of the Australasian information security workshop conference on ACSW frontiers 2003, Volume 21. 49-58.

Manavalan, M. (2018). Do Internals of Neural Networks Make Sense in the Context of Hydrology? . Asian Journal of Applied Science and Engineering, 7, 75-84. Retrieved from https://upright.pub/index.php/ajase/article/view/41

Manavalan, M. (2019). Using Fuzzy Equivalence Relations to Model Position Specificity in Sequence Kernels. Asian Journal of Applied Science and Engineering, 8, 51-64. Retrieved from https://upright.pub/index.php/ajase/article/view/42

Manavalan, M. (2019a). P-SVM Gene Selection for Automated Microarray Categorization. International Journal of Reciprocal Symmetry and Physical Sciences, 6, 1-7. Retrieved from https://upright.pub/index.php/ijrsps/article/view/43

Moss, D., Likely, F., Sriramesh, K. and Ferrari, M. A. (2017). Structure of the public relations/communication department: Key findings from a global study. Public relations review, 43(1), 80-90.

O'Gorman, E., Van Dooren, T., Münster, U., Adamson, J., Mauch, C., Sörlin, S., Armiero, M., Lindström, K., Houston, D. and Pádua, J. A. (2019). Teaching the environmental humanities: International perspectives and practices. Environmental Humanities, 11, 427-460.

Subramanya, S. and Yi, B. K. (2006). Digital rights management. IEEE potentials, 25, 31-34.

Wager, S. (2005). Digital asset management, media asset management, and content management: From confusion to clarity. Journal of Digital Asset Management, 1, 40-45.

Zerfass, A. and Volk, S. C. (2018). How communication departments contribute to corporate success: The communications contributions framework. Journal of Communication Management, Vol. 22 No. 4, pp. 397-415. https://doi.org/10.1108/JCOM-12-2017-0146

Zur, O., Williams, M. H., Lehavot, K., \& Knapp, S. (2009). Psychotherapist self-disclosure and transparency in the Internet age. Professional Psychology: Research and Practice, 40(1), 22 30. https://doi.org/10.1037/a0014745

$$
--0--
$$

Online Archive:

https:/i-proclaim.my/journals/index.php/gdeb/issue/archive 